\title{
ARTIGO
}

dol htps://doi.org/10.22481/praxisedu.v15i34.5628

\section{DESIGN E APRENDIZAGEM A PARTIR DA EXPERIÊNCIA: OFICINA DE CINEMA DE ANIMAÇÃO COM MATERIAIS NATURAIS}

\author{
DESIGN AND EXPERIENCIAL LEARNING: WORKSHOP OF ANIMATION FILM \\ WITH NATURAL MATERIALS
}

\author{
DISEÑO Y APRENDIZAJE A PARTIR DE LA EXPERIENCIA: TALLER DE CINE DE \\ ANIMACIÓN COM MATERIALES NATURALES
}

\author{
Julia Teles da Silva \\ Universidade Federal de Campina Grande - Brasil
}

Jackeline Lima Farbiarz

Pontifícia Universidade Católica do Rio de Janeiro - Brasil

\begin{abstract}
Resumo: $\mathrm{O}$ artigo apresenta a experiência da oficina de cinema de animação com materiais naturais, dada para crianças de 6 a 8 anos em escola de ensino fundamental - oficina que tem como base metodologias de educação desenvolvidas dentro do campo do Design - metodologias que priorizam a cocriação entre diferentes pessoas, em lugar da criação individual, e a experimentação, em lugar da abstração. Fundamentamos essa metodologia através do pensamento de Ivan Illich, que fala da importância do aprendizado colaborativo, a partir da convivência entre as pessoas, e de Buckminster Fuller, que fala da importância do aprendizado através da experimentação, como alternativa à abstração excessiva. Também trazemos noções de design para a sustentabilidade, ao repensar o uso de materiais na educação. Trata-se de uma pesquisa interdisciplinar, levando em conta a natureza interdisciplinar do Design, envolvendo as áreas da Educação, Artes Plásticas, Cinema, Fotografia, Sustentabilidade. É apresentada a experiência da oficina com base nesses olhares.
\end{abstract}

Palavras chave: Cinema de animação; Educação infantil; Materiais naturais.

\begin{abstract}
The paper presents the experience of an animation film with natural materials workshop, given to children from 6 to 8 years in an elementary school - a workshop that is based on education methodologies developed within the field of Design - methodologies that prioritize the co-creation between different people, instead of individual creation, and experimentation rather than abstraction. We base this methodology on the thinking of Ivan Illich, who talks about the importance of collaborative learning, based on conviviality, and of Buckminster Fuller, who talks about the importance of learning through experimentation rather than excessive abstraction. We also bring ideas from design for sustainability by rethinking the use of materials in education. It is an interdisciplinary research, taking into account the interdisciplinary nature of Design, involving the areas of Education,
\end{abstract}


Arts, Cinema, Photography, Sustainability. The experience of the workshop is presented based on these views.

Keywords: Animation film; Child education; Natural materials.

Resumen: El artículo presenta la experiencia del taller de cine de animación con materiales naturales, dada para niños de 6 a 8 años en escuela de enseñanza fundamental - taller que tiene como base metodologías de educación desarrolladas dentro del campo del Diseño - metodologías que priorizan la co-creación entre diferentes personas, en lugar de la creación individual, y la experimentación, en lugar de la abstracción. La metodología está basada en el pensamiento de Ivan Illich, que habla de la importancia del aprendizaje colaborativo, a partir de la convivencia entre las personas, y de Buckminster Fuller, que habla de la importancia del aprendizaje a través de la experimentación, como alternativa a la abstracción excesiva. También traemos nociones de diseño para la sostenibilidad, al repensar el uso de materiales en la educación. Se trata de una investigación interdisciplinaria, teniendo en cuenta la naturaleza interdisciplinaria del Diseño, involucrando las áreas de Educación, Artes Plásticas, Cine, Fotografía, Sostenibilidad. Se presenta la experiencia del taller a partir de estas miradas.

Palabras clave: Cine de animación; Educación infantil; Materiales naturales.

\section{Introdução}

Esse artigo apresenta uma proposta de ensino através das interações e da experiência, observando o caso da oficina de cinema de animação com materiais naturais, realizada por uma das autoras na Escola Pedra da Gávea, no Rio de Janeiro, de 2015 a 2018 - uma oficina que trabalha aprendizados relacionados ao Design para a primeira infância.

Essa oficina tem uma metodologia relacionada à experiência de Design e Educação que são trabalhados no Departamento de Design da PUC-Rio, com destaque para o LINCDesign (Laboratório de Linguagem, Interação e Construção de sentidos no Design), que nos traz um olhar sobre a interação entre as pessoas e os objetos. A colaboração entre os diferentes sujeitos para a criação de um objeto é fundamental. Essa pesquisa trabalha com a ideia de que o aprendizado ocorre de maneira prática e interativa, com destaque para as diferentes relações estabelecidas no processo de aprendizado - das pessoas umas com as outras, e das pessoas com objetos.

Entendemos o Design como uma área interdisciplinar, que tem por característica não estar limitado a uma única área de conhecimento, mas por permear diferentes áreas, podendo atuar em muitos campos. A própria falta de limites claros do Design pode ser vista como uma qualidade do campo, em vez de uma falha. E essa liberdade da área é o que possibilita novas criações. Nessa pesquisa, trabalhamos o Design em sua relação com diferentes campos, como 
a educação, o cinema, a fotografia, as artes plásticas, a sustentabilidade. Levamos em conta que pensar, através do Design, a criação de um projeto coletivo com crianças, envolve tanto aspectos sociais - o diálogo, a troca de ideias e coautoria - quanto aspectos materiais - a manualidade, a descoberta da característica, origem e possibilidade criativa de cada material.

No artigo, recuperamos pensamentos Ivan Illich e Buckminster Fuller, para sustentar uma visão de educação a partir das interações e da experiência. Por meio das ideias apresentadas por esses autores, refletimos sobre a oficina realizada com crianças de seis e sete anos. O artigo reflete sobre a experiência com essa oficina, que tem um caráter interdisciplinar e projetual, mesclando cinema, fotografia, cenografia, artes plásticas.

Assim, o problema abordado no artigo é como uma metodologia de ensino colaborativa e experimental proposta pelo Design pode ser aplicada a uma oficina interdisciplinar com crianças em idade de alfabetização.

Para a elaboração do artigo, a metodologia empregada foi a de revisão teórica dos autores que falam sobre educação e experiência e o relato do trabalho com a oficina, fazendo uma relação entre a oficina, o aprendizado a partir da experiência e a concepção de Design em que nos ancoramos.

\section{Ivan Illich e Buckminster Fuller: diálogos com a educação}

Um ensino menos focado na instituição e na teoria, e mais baseado na autonomia, nas interações e na experiência; essa é uma proposta que vemos crescer na atualidade e que era defendida por Ivan Illich ainda na década de 1970, em livros como "Sociedade sem escolas" (1970), "A Convivencialidade"(1973) e "Némesis da medicina" (1976). Sobre o autor, podemos afirmar ser ele um ferrenho crítico da sociedade industrial, que, em sua concepção, centraliza a produção e burocratiza o conhecimento, tornando as pessoas dependentes e progressivamente destituídas de seu potencial criativo. Para Illich, as instituições levariam à perda da autonomia das comunidades, pois elementos que antes eram de sua alçada, como a educação das crianças, o cuidado dos enfermos e a produção de bens, vão progressivamente sendo institucionalizados e se distanciando dos auspícios das pessoas que, consequentemente, vão perdendo a autonomia.

Não detendo suas reflexões nos aspectos críticos apenas, Illich (1973) considera fundamental uma revisão da formação da sociedade, propondo uma sociedade convivencial. Em sua proposição, essa sociedade teria como característica básica uma participação mais ativa das pessoas em todos os aspectos da vida, participação amparada pela convivência e 
fraternidade entre as pessoas que, em sua acepção, contariam mais umas com as outras e menos com as máquinas. Para o autor, no sistema social que critica, as decisões são tomadas de forma centralizada, determinando o isolamento e a dependência das pessoas. Diferente disso, na sociedade convivencial, cada pessoa poderia se expressar, e a coletividade teria o poder de tomar as decisões. Além disso, as trocas interpessoais teriam maior presença - as pessoas teriam que reaprender a depender umas das outras, em vez de depender da indústria. Elas deveriam compreender que podem ser mais felizes se trabalharem juntas e prestarem assistência mútua (ILLICH, 1973).

Illich destaca a importância da educação e da troca de informações de forma não institucionalizada. Ele faz uma forte crítica ao saber institucional em nossa sociedade e propõe o saber convivencial, que tem sua base na aprendizagem espontânea e não programada. Para o autor, da forma como o conhecimento e a produção são organizados, poucas pessoas têm condições de saber como funcionam certos aparelhos complexos, estando destituídas assim de autonomia. Diferente disso, na sociedade convivencial, todos poderiam aprender, de maneira não institucional, a lidar com as ferramentas disponíveis.

Da década de 70 aos dias de hoje, muito do pensamento de Ivan Illich direta ou indiretamente vem sustentando as políticas públicas para a Educação Básica, mesmo sendo este autor um crítico da institucionalização do saber. Certo é que palavras como autonomia, competências como "levar o aluno a aprender a aprender", expressões como "respeitar a individualidade do aluno", fazem parte dos Parâmetros Curriculares Nacionais e constituemse como premissas básicas indiscutíveis.

Tal consciência, contudo, muitas vezes, vai de encontro a um conceito valorizado de Escola como instituição, pois ainda hoje, há no cotidiano, valorização da centralização de informações e padronização dos aprendizados. Deixa-se ainda hoje em várias opções de modelos de ensino pouco espaço para a experimentação, a criatividade e a individualidade. $\mathrm{O}$ conhecimento ainda é reconhecido como originário de um lugar centralizado, desconsiderando a diversidade, mesmo quando leis de inclusão já se façam presentes no dia a dia da Escola.

Assim, apresenta-se como uma contradição buscar a autonomia, valorizada em Illich, em um lugar que se configura como institucionalizado, com hierarquias próprias, padrões e ritmos, em muitos dos seus modelos pré-estabelecidos. Na perspectiva de Illich, não haveria possibilidade de autonomia vinculada a institucionalização, ampliando assim o descompasso entre os Parâmetros vigentes e seu pensamento. 
Se então a princípio o pensamento de Illich e a Escola na contemporaneidade não encontrariam afinidade, o que se observa é que o autor antecipou o conceito de sociedade convivencial que vem sendo valorizado em muitos modelos de ensino e vivenciado pelas pessoas em seus cotidianos principalmente por meio das novas tecnologias de comunicação e interação. Conviver, rever o conceito de tempo e espaço, produzir em detrimento de receber são competências que ganham espaço no cenário atual em busca de levar o aluno a aprender a aprender a desenvolver sua autonomia para trocar conhecimento com diferentes pessoas e fontes, entendendo que a escola não é um espaço único de detenção e passagem do conhecimento, mas um espaço propício para o ganho de ferramentas para aprender de diferentes fontes e de diferentes maneiras.

Nesta perspectiva, para o ensino-aprendizagem, a colaboração e troca de conhecimentos são fundamentais, seja fora da escola ou dentro dela. Portanto, em vez de uma educação focada no rendimento do indivíduo, na valorização do ensino convivencial, podemos pensar em um rendimento focado nas colaborações entre os alunos, entre alunos e mediadores e entre alunos-mediadores-mundo.

Se hoje conceitos desenvolvidos em Illich encontram ressonância nas diretrizes governamentais para a Educação, outros autores entendem que ainda há um grande percurso a ser percorrido antes que de fato a autonomia como competência do aluno seja uma realidade cotidiana. Buckminster Fuller, designer, engenheiro, arquiteto e educador estadunidense é um desses autores. Ele critica as grandes organizações, dentre elas a Escola, vendo nelas apenas um meio de perpetuação do poder e da fortuna das pessoas que as controlam (SIEDEN, 1989). Segundo o autor, o atual sistema educacional se mantém muito teórico - uma teoria que simplifica e torna as coisas abstratas. Ele acredita que a melhor maneira de aprender sobre o mundo e sua geometria é a partir de modelos físicos, que as pessoas possam ver e pegar, e não através de pura teoria. Fuller sempre levava pequenos modelos físicos para as suas palestras, que facilitavam o entendimento do que estava falando. Segundo o autor, embora haja modelos educacionais que inserem os sujeitos no centro do conhecimento e também as interações deles no meio, também prevalecem modelos que tendem a tornar as ciências completamente abstratas e distantes do contexto da vida das pessoas.

Fuller acreditava que seria importante a educação focar-se centralmente na experiência do indivíduo e nas relações presentes nessa experiência. Isso daria aos estudantes uma visão muito mais ampla dos princípios das ciências e lhes facilitaria aplicar, em suas vidas profissionais e cotidianas, a educação recebida. Seu ponto de vista decorre de sua convicção de que a maneira que as crianças têm de aprender sobre o mundo é sempre experimental, 
usando tentativa e erro - e não aceitando o conhecimento abstrato que alguém apresenta a elas. O autor ressalta que a experimentação traz a ideia de que erros não são algo problemático. Assim, é experimentando e errando que elas adquirem mais conhecimento. E Fuller complementa seu pensamento, ressaltando que as crianças também têm uma curiosidade natural de entender tudo, partindo das grandes coisas.

Para sustentar seus argumentos acerca da distância que a educação ainda tem que percorrer para de fato constituir o aprendizado da autonomia por meio da experiência, Fuller dá o exemplo de como a geometria e as formas geométricas ainda são ensinadas de uma forma extremamente abstrata. Segundo ele, por exemplo, qualquer forma geométrica deve ser desenhada em uma superfície concreta, e não em um plano ideal. Fuller conta que, em suas investigações, pediu para um garoto desenhar um triângulo no chão. O garoto desenhou e Fuller perguntou o que ele via, percebendo pela resposta que faltavam elementos de formação para o garoto compreender que, se o triângulo é uma área definida por três retas, formando três ângulos, havia o triângulo pequeno, e outro triângulo muito maior - que compreenderia o resto da terra inteira, que também estaria limitado por aquelas três retas e três ângulos.

Figs. 1 e 2: Garoto desenha triângulo na terra; e triângulo visto com dimensões maiores, desenhado em uma esfera
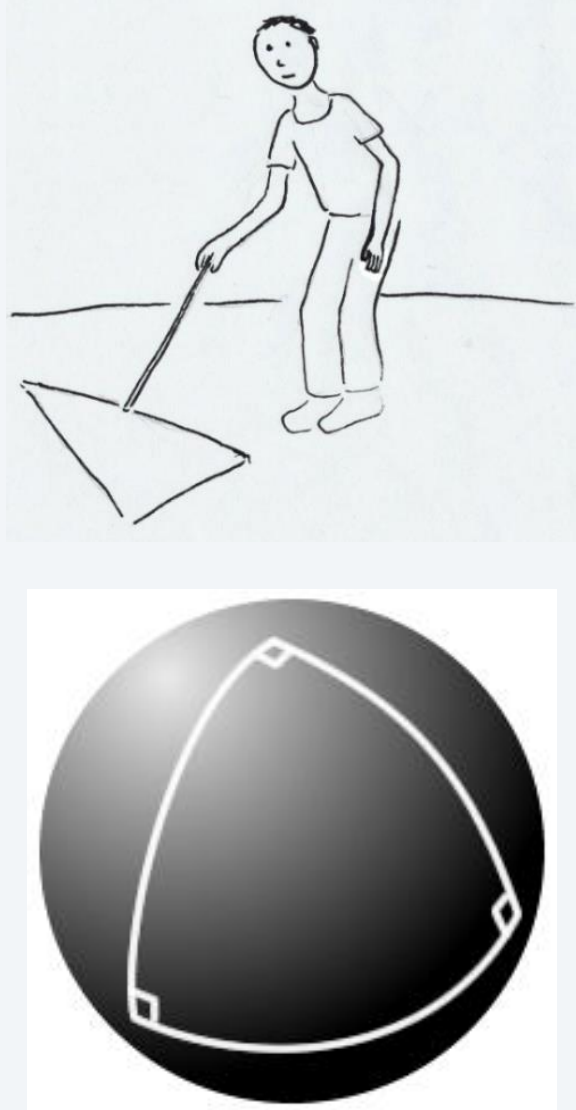
Com isso, Fuller demonstrou que ainda prevalece um ensinar que reduz o mundo em limites artificiais, que se distancia de uma perspectiva ampla.

Fuller acreditava que o sistema educacional, em que há o privilégio do específico sobre o todo, amplia-se as competências de especialização e abstração, fazendo com que as pessoas não levem em conta suas experiências pessoais e se sintam distantes da natureza e dos outros indivíduos. Educação essa que contribui para que os sistemas humanos continuem a criar fronteiras entre 'nós' e 'os outros'. (SIEDEN, 1989)

Fuller acreditava na importância de se ter um olhar geral sobre o mundo e que seria importante criar 'generalistas', em vez de especialistas. Mas, pelas suas observações, os melhores alunos são levados a se tornarem especialistas em algo, enquanto os generalistas, que têm um olhar sobre o todo, não têm muito respeito no mundo.

No caso da educação infantil, recorte onde está inserida a proposição do presente artigo, a experimentação também é essencial, como Fuller coloca. O natural da criança é experimentar, sem medo de errar, descobrindo sempre novas coisas. Fuller acreditava que todas as crianças eram geniais, mas que a educação lhes tirava a genialidade em seus primeiros anos de vida.

As crianças nascem como verdadeiros cientistas. Elas espontaneamente experimentam e experienciam e experimentam novamente. Elas selecionam, combinam e testam, buscando encontrar ordem em suas experiências - "qual é o mais de todos? Qual é o menos de todos?" Elas cheiram, provam, mordem e tocam para testar a dureza, a maciez, a flexibilidade, a aspereza, a suavidade, o frio, o calor: elas carregam, sacodem, socam, espremem, empurram, esmagam, esfregam e tentam desmontar as coisas. (FULLER, 2010, p. 169) ${ }^{1}$

Para Fuller, a criança naturalmente tem o olhar do cientista - que quer adquirir conhecimento através da experimentação, daquilo que pode ser demonstrado e repetido. Elas adquirem informação através da tentativa e do erro, sempre aprendendo com os erros. Mas o sistema educacional as faz aprender a partir da abstração e de informações previamente dadas, não deixando espaço para o erro.

Dentro do possível, na visão de Fuller, é importante lidar com modelos e situações reais, sem teorização excessiva. Aprender diretamente com modelos, em uma realidade tridimensional é importante, diante de um ensino que torna tudo bidimensional, cabendo em

\footnotetext{
1 Original em inglês: "Children are born true scientists. They spontaneously experiment and experience and reexperience again. They select, combine, and test, seeking to find order in their experiences - "which is the mostest? which is the leastest?" They smell, taste, bite, and touch-test for hardness, softness, springiness, roughness, smoothness, coldness, warmness: they heft, shake, punch, squeeze, push, crush, rub, and try to pull things apart.
} 
uma folha ou tela, reduzindo a realidade.

Para o autor, é importante que essa experimentação prática esteja presente, já que a curiosidade é natural das crianças. Na interação uns com os outros e com os objetos, os alunos podem aprender de forma prática, a partir de sua curiosidade natural.

\section{A oficina de animação com materiais naturais}

Foi tomando como pressupostos as visões de Illich e Fuller acerca da Escola como ensino institucionalizado de valorização da especialização e da abstração que se buscou estabelecer pontes entre Design e Educação com vistas a contribuir para o desenvolvimento de situações de ensino-aprendizagem colaborativas, com vistas a convivência, autonomia e experimentação. Nos baseamos em metodologias projetuais colaborativas de Design, que dialogam com o campo da educação. Neste sentido, descreveremos a seguir a Oficina de cinema de animação com materiais que teve início no primeiro semestre de 2015, na Escola Pedra da Gávea.

A oficina teve a proposta de ensinar através da prática e da experimentação, as possibilidades de diferentes materiais e da realização do cinema de animação. Trata-se de uma aula interdisciplinar, em que trabalhamos com um projeto e cada etapa desse projeto tem características próprias.

A oficina foi ministrada tomando por base a metodologia design participativo, por uma professora com doutorado em Design na área de concentração Design e Sociedade que em suas pesquisas discute métodos convivenciais e colaborativos de ensino-aprendizagem, criando a partir de materiais naturais.

O Design Participativo é uma proposta metodológica pioneira de desenvolvimento de projeto adotada em disciplinas de projeto básico do curso de Design da PUC-Rio, fundado em 1978. Essa metodologia de criação considera o usuário como sujeito, e o Designer e os usuários são ambos coautores, trabalhando em parceria, através de um diálogo em que todos têm a acrescentar na criação do objeto.

A opção pela metodologia participativa tem em vista o entendimento do Design como campo de natureza tecnológica e vocação interdisciplinar cuja metodologia de desenvolvimento de projetos se baseia na coautoria, entendendo que todos os agentes envolvidos no processo de construção do conhecimento possuem expertises individuais que somadas atendem a problemas complexos e multifacetados como o ensinar a aprender a aprender para a autonomia e a experiência. 
O Design, com seu caráter interdisciplinar, pensa tanto nos aspectos sociais quanto materiais dos objetos e criações. Assim, se o Design Participativo desenvolve a coautoria e a colaboração na criação de um projeto, não podemos deixar de levar em conta o aspecto material - qual o material utilizado, de onde ele vem, como manuseá-lo, para onde vai após descartado. O Design para a sustentabilidade traz esse olhar mais amplo para o objeto e as criações. É importante ter a consciência de onde vem cada material e pensar que materiais podem ser usados para se criar um projeto mais sustentável.

A Escola Pedra da Gávea, no Rio de Janeiro, vai da creche ao Ensino Fundamental I. A aula de animação ocorre uma vez por semana, e as turmas tiveram inicialmente alunos de 6 anos, passando depois a alunos de 7 e 8 anos, havendo uma continuidade, à medida que os alunos foram crescendo. Inicialmente, as turmas eram menores, de 7 a 8 alunos, mas depois as turmas cresceram e duas turmas se fundiram, chegando a 22 alunos.

O curso começa com aulas práticas para se aprender o princípio básico do cinema - a criação de imagens em movimento a partir de fotografias quadro a quadro. Os alunos começaram fazendo exercícios de construção de brinquedos óticos - flipbook, taumatrópio e dobradinha - que ajudam a entender como se constrói a imagem em movimento. Trata-se de uma etapa importante para se desenvolver o olhar para observar como as mudanças de um quadro para o outro são muito pequenas.

Fig. 3: Exercício de montagem de flipbook a partir de imagens que mudam quadro a quadro.

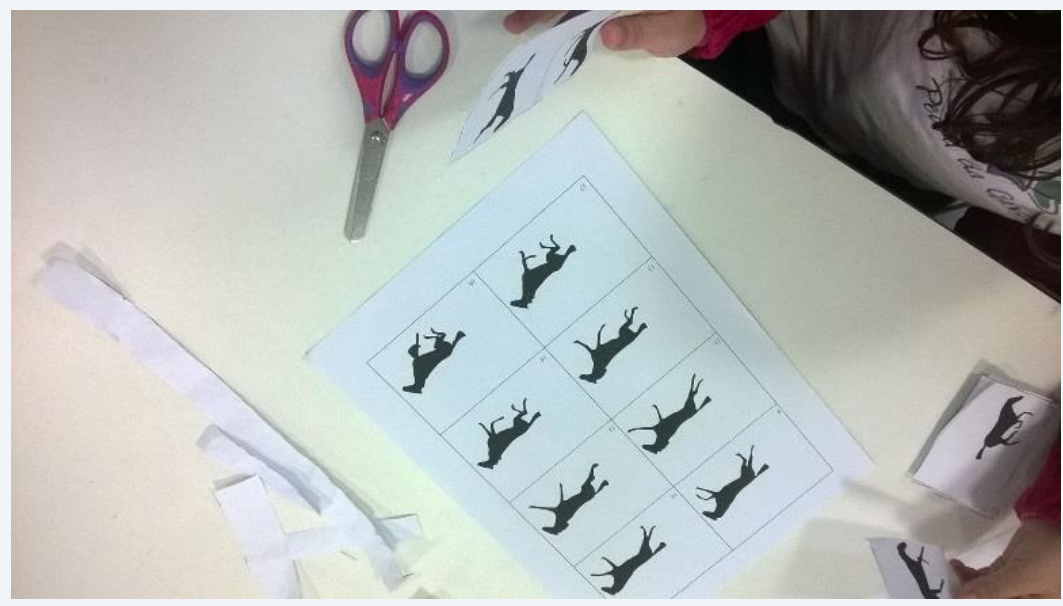

Os brinquedos óticos trazem um contato com o funcionamento do cinema, e o aprendizado inicial de que ele é sempre feito a partir de uma sequência de fotos com uma diferença muito pequena de quadro a quadro. 
Em uma etapa seguinte, realizamos a criação de composições com diversos materiais, seguida pela fotografia e animação dessas composições. Os filmes são feitos coletivamente cada aluno participa com um elemento, mas a obra é sempre do conjunto das crianças. A edição filmes, com a as fotos quadro a quadro colocadas em sequência, é feita posteriormente pela professora em um programa de edição de vídeo.

A ideia da oficina é trazer para as crianças uma reflexão prática sobre os materiais usados - em um mundo em que elas lidam sobretudo com materiais processados e objetos já moldados em formatos prontos, a proposta é trazer a experiência de criar, a partir de suas próprias mãos, formas, composições e objetos com materiais naturais ou reutilizados. Há uma prioridade do uso de materiais naturais, não processados industrialmente. Também são reutilizados materiais que seriam descartados, e usados também, de forma complementar, materiais de papelaria, como lápis, lápis de cor, caneta hidrocor, cartolina, cola. Assim, as crianças podem refletir sobre o potencial criativo desses materiais e aprender, a partir da manualidade, um pouco sobre as características de cada material. Assim, fizemos animações utilizando argila, terras coloridas, materiais coletados na pracinha (folhas, flores e galhos), massinha natural (feita a partir de farinha de trigo), tintas naturais (feitas pelos alunos a partir de pigmentos de beterraba, couve e açafrão), recortes de revistas e jornais, palitos de bambu, garrafas pet recortadas, retalhos de tecidos, grãos, fios de cobre usados, papel machê, dentre outros. Os alunos refletem sobre como muitos materiais são feitos (como as tintas de pigmento natural, a massinha caseira e o papel machê) e aprendem sobre os materiais e suas possibilidades na prática e vão entendendo suas características e como lidar com eles. Em geral, a professora leva os materiais que serão trabalhados, mas, no caso dos materiais coletados pelos alunos na pracinha, há um exercício interessante de se abrir o olhar para possibilidade de criação com materiais que passariam despercebidos, como galhos e folhas.

Figs. 4, 5 e 6: Exemplos de diferentes materiais trabalhados nas animações: grãos, bonecos de arame, flores, areia, tintas de pigmentos naturais

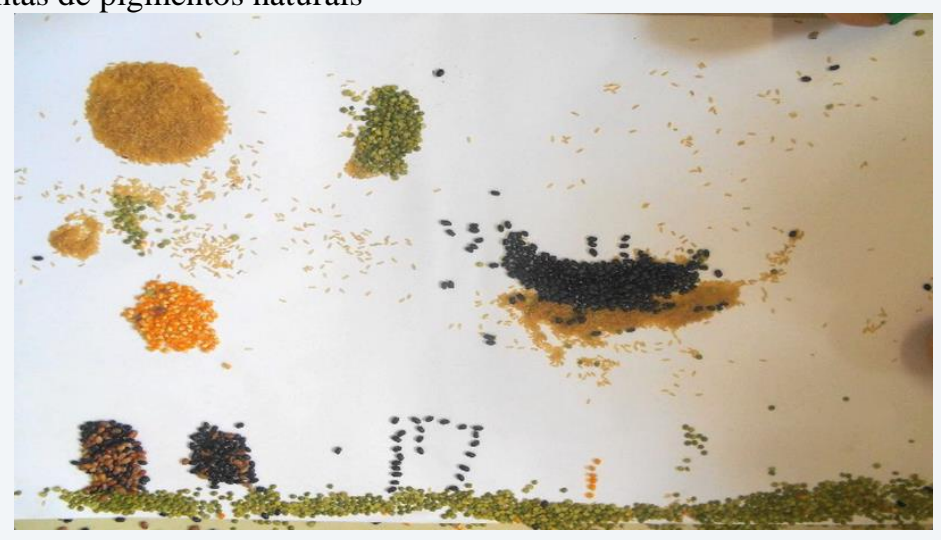



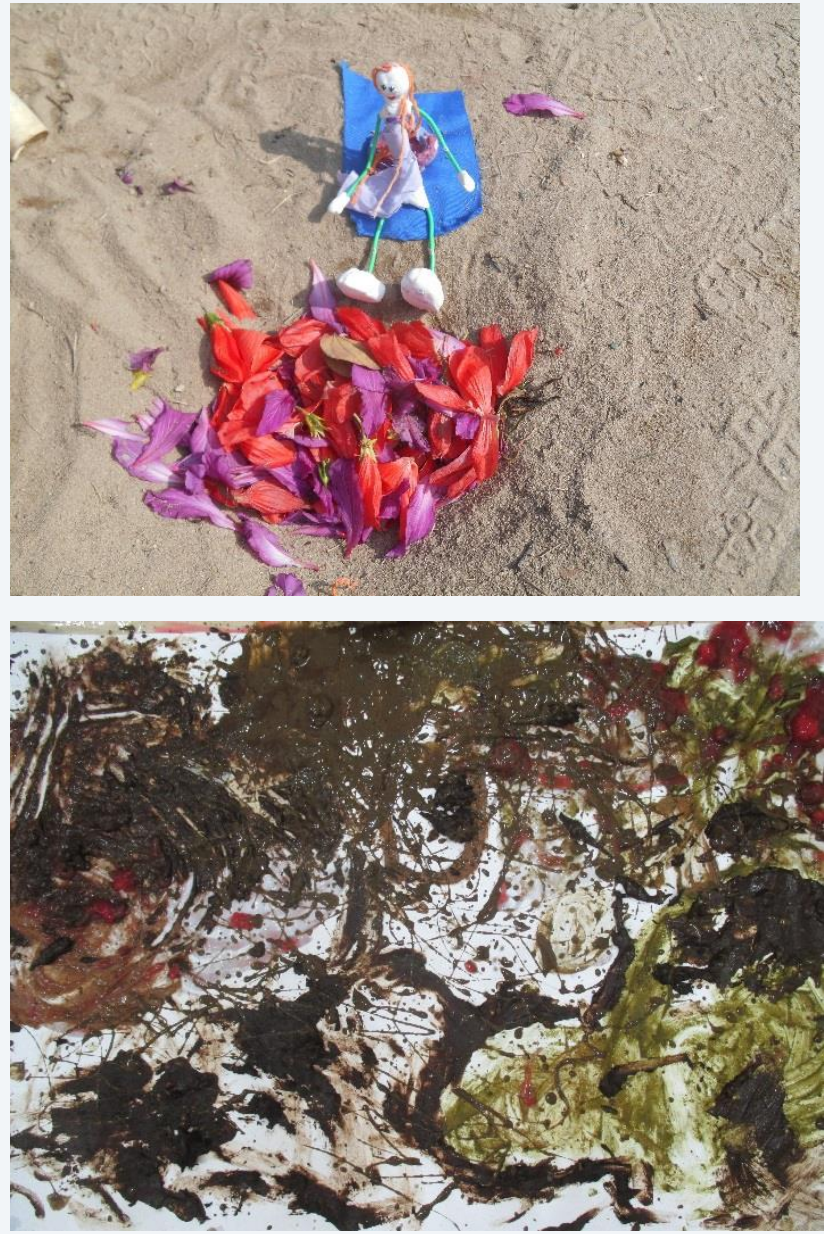

Os alunos trabalham bastante a manualidade para lidar com esses materiais, transformando-os em pinturas, composições abstratas, cenários e personagens.

Figs. 7, 8 e 9: Os trabalhos envolvem o manualidade, com a manipulação de diferentes materiais.

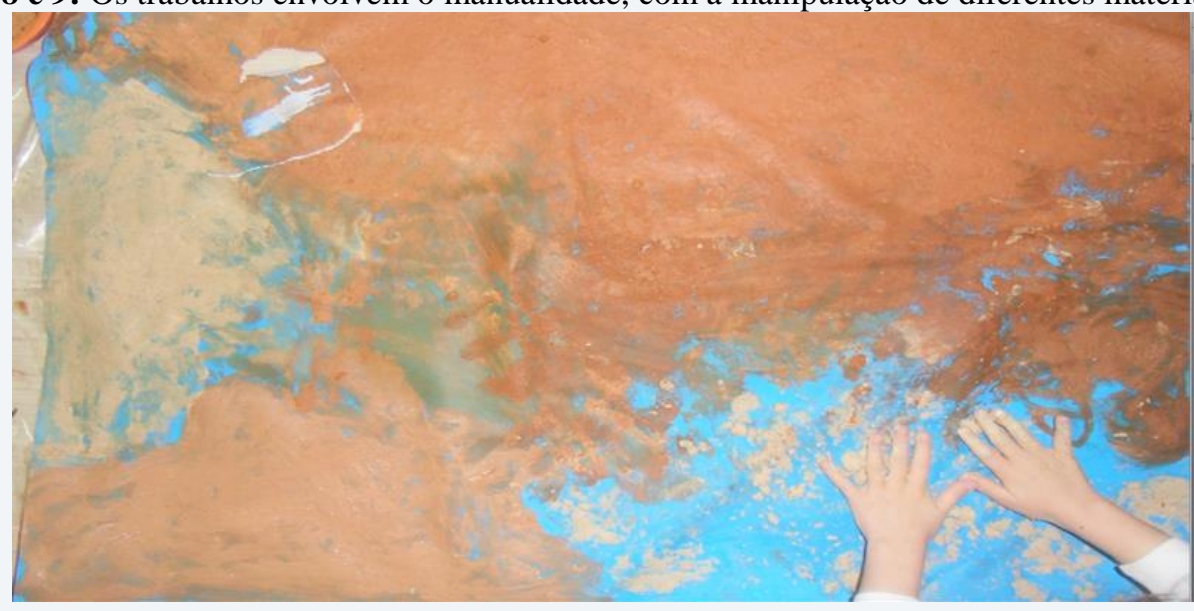



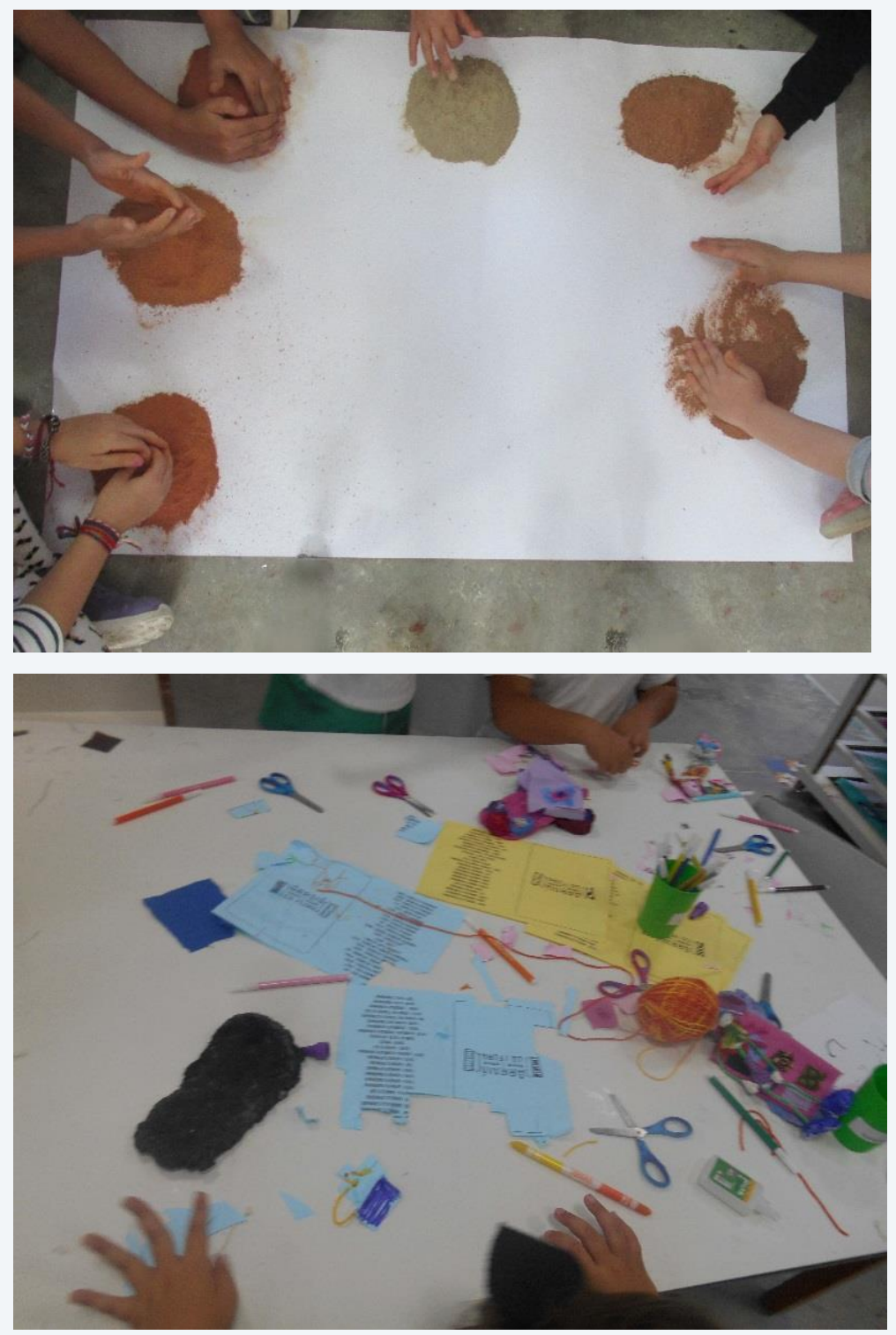

Como diz o ex-pesquisador da PUC-Rio, Carlos Côrtes, que desenvolveu um trabalho educativo com crianças de pré-escola trabalhando com materiais naturais, "Através do gesto e do objeto, a criança se apropria e também se abre para o mundo, projeta-se para além de seus limites corporais, sendo essa projeção a base para todo desejo de expressão e comunicação". (CÔRTES, 1999, p. 33). Côrtes fez o projeto da casa de bambu e barro usando a metodologia do antigo laboratório LOTDP (Laboratório e Oficina de Treinamento e Desenvolvimento de Protótipos - atualmente LILD - Laboratório de Investigação em Livre Desenho). O pesquisador colocou que o manuseio do barro para a construção de uma casinha ampliava a percepção e a criatividade das crianças, entendendo que a inteligência prática e gestual é a primeira a ser desenvolvida por crianças (CÔRTES, 1999). 
A partir dessa experiência, a criança ganha uma noção prática de sustentabilidade - ela tem uma oportunidade de pensar sobre a origem dos materiais e as possibilidades de utilização que eles têm.

$\mathrm{Na}$ aula, as crianças trabalham com diferentes materiais e, mais para frente, fazem bonecos - de papel cartão ou de arame e massinha. Esse é um processo importante para a criança aprender mais sobre o mundo. Walter Benjamin (2009) explica que a criança deseja saber como são feitos os brinquedos - e os brinquedos não precisam ser necessariamente muito realistas - mas que as crianças são instigadas por imaginar como são feitos. Ao mesmo tempo, o autor explica que as crianças se dão muito bem com materiais tradicionais, não sendo necessário o uso de materiais que criem uma finalização perfeita aos brinquedos: "madeira, ossos, tecidos, argila representam, nesse microcosmo os materiais mais importantes" (BENJAMIN, 2009, p. 92) - e a partir de materiais simples, a imaginação da criança já é estimulada.

Crianças são especialmente inclinadas a buscarem todo local de trabalho onde a atuação sobre as coisas se processa de maneira visível. Sentem-se irreversivelmente atraídas por detritos que se originam da construção, do trabalho no jardim ou em casa, da atividade do alfaiate ou do marceneiro. Nesses produtos residuais, elas reconhecem o rosto que o mundo das coisas volta exatamente para elas, e somente para elas. Neles, estão menos empenhadas em reproduzir as obras dos adultos do que em estabelecer entre os diferentes materiais, através daquilo que criam em suas brincadeiras, uma relação nova e incoerente. Com isso, as crianças formam seu próprio mundo das coisas, um pequeno mundo inserido no grande. (BENJAMIN, 2009, p. 103-104)

Após criarem as composições com os materiais, os alunos passam para a etapa da fotografia quadro a quadro. O processo da fotografia é um exercício que exige concentração e paciência. Os alunos se mostram mais inquietos nessa etapa - a fotografia requer concentração e é uma atividade bem mais intelectual do que manual. E a fotografia quadro a quadro, especialmente, em que a composição deve mudar muito pouco a cada foto, é muito pouco dinâmica e não envolve a manualidade das crianças.

Os alunos estão em fase de alfabetização e em alguns vídeos, para os créditos finais, eles escrevem as letras iniciais de seus nomes com os materiais utilizados, o que lhes traz um novo olhar para a escrita e para as possiblidades de uso daqueles materiais. 
Fig. 10: Os alunos estão em fase de alfabetização e têm a oportunidade de experimentar a escrita com outros materiais.

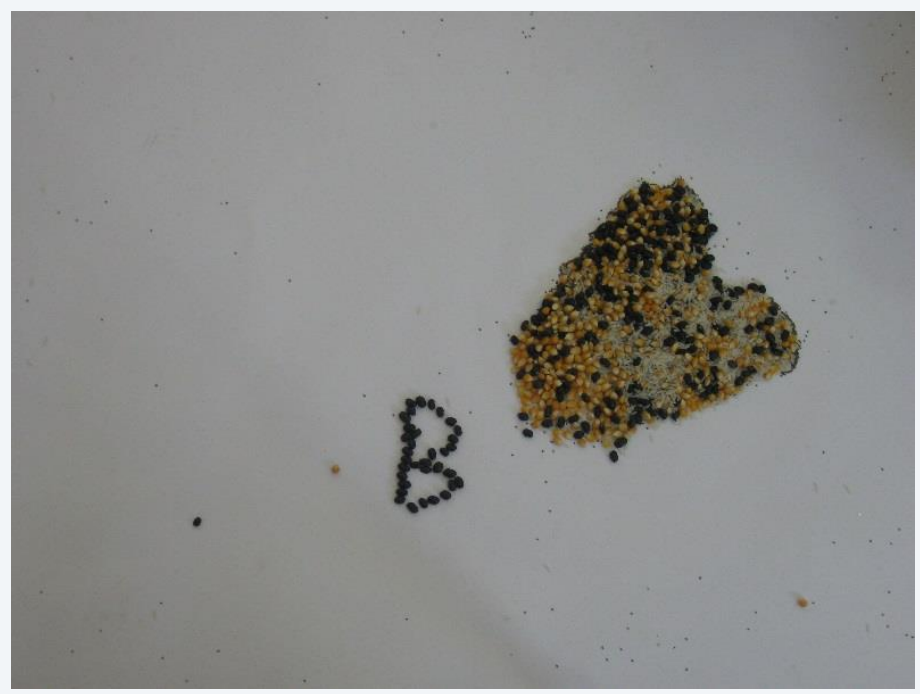

A proposta é que o curso mostre às crianças como elas podem criar uma obra coletiva a partir da criação de cada um e como os personagens a que eles dão forma podem ganhar vida em um vídeo de animação. A animação é um trabalho que exige paciência e detalhismo na fotografia quadro a quadro, dando às crianças a dimensão do trabalho que é a criação de qualquer obra mais complexa. Todos os alunos têm uma criação individual, mas os filmes sempre são feitos de forma coletiva - são resultado do trabalho de todos, sendo uma obra colaborativa e de interação entre as crianças. Assim, as obras não têm um resultado focado nos indivíduos, mas são um trabalho convivencial, em que a colaboração entre os alunos é essencial para a criação dos filmes.

Fig. 11: Os materiais, como os grãos, formam uma única composição a ser fotografada, a partir da colaboração de todos os alunos.

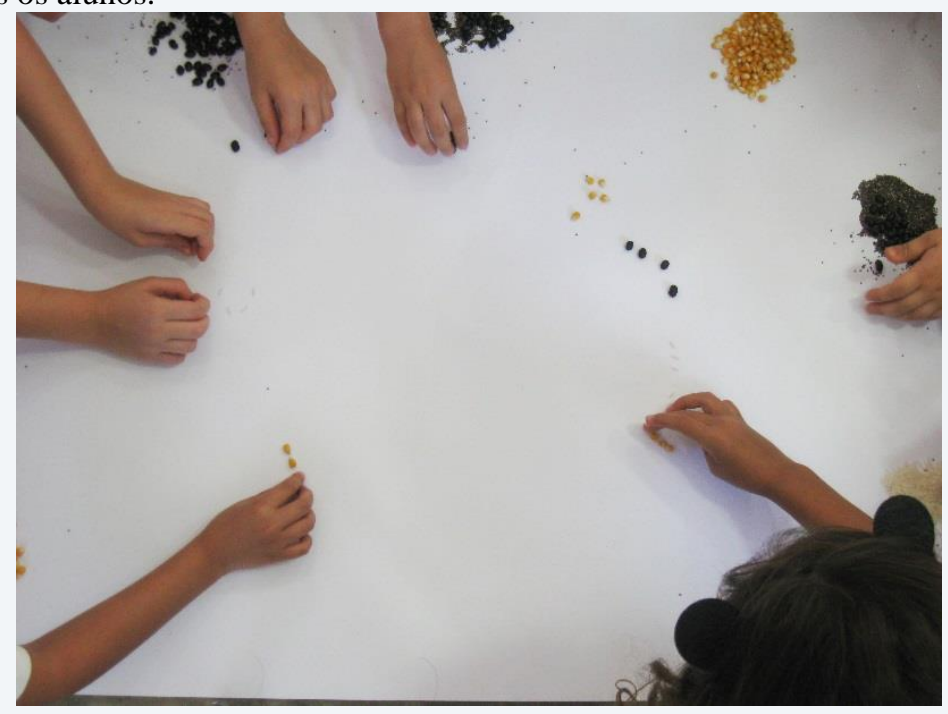


Fig. 12: Dependendo do projeto, os alunos trabalham mais sua criação individual, como nos bonecos de arame. Mas todos participam de um único filme.

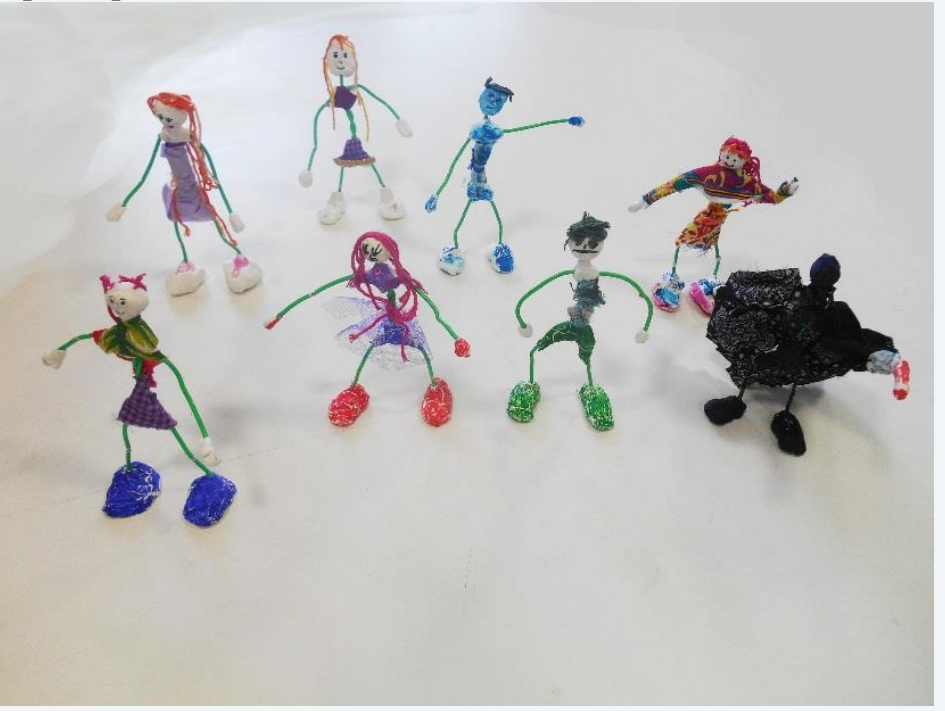

\section{Considerações Finais}

A partir das propostas de educação que vimos em Illich e Fuller, podemos refletir sobre as possibilidades da educação baseada na experiência e nas interações, tendo como exemplo o trabalho realizado na oficina de animação com materiais naturais. Na oficina, realiza-se a proposta de uma educação interdisciplinar e que tem um aprendizado prático, a partir do gestual e manipulação direta dos materiais. Como vimos, Fuller reitera a importância do aprendizado a partir da experiência, evitando abstrações e lidando diretamente com modelos físicos. A oficina de cinema de animação busca ensinar sobre a manipulação dos materiais e sobre a criação cinematográfica de forma prática, a partir da experiência dos alunos. Tentamos evitar fragmentar a realidade em disciplinas, trabalhando em uma única aula com diferentes questões - a origem dos materiais, a criação de formas a partir desses materiais, a composição de quadro, a cenografia, a criação de personagens, a fotografia. A ideia é não fragmentar a realidade artificialmente, mas entender como diferentes elementos se integram para a criação de uma obra. Pudemos perceber a importância de um ensino não abstrato, e a relação entre a infância e a aprendizagem através do manuseio e criação diretamente a partir dos materiais. Percebemos que a fotografia, como etapa que não envolve a manualidade, mas apenas o olhar, desperta menos o interesse das crianças e as deixa menos envolvida, provavelmente por ser uma atividade muito abstrata para a idade.

Percebemos a importância de a educação não ser focada apenas no indivíduo, separando o aluno dos 'outros'. Como vimos com Illich, as trocas são fundamentais, e a maior 
parte do conhecimento se dá a partir das trocas informais entre as pessoas. Apesar da oficina ser dentro da escola, a proposta é de que os alunos tenham uma experiência de trabalhar em um projeto coletivo, em que a colaboração de todos é fundamental. Entendemos a importância de não focar os avanços no rendimento individual dos alunos, mas nas trocas que eles estabelecem uns com os outros, e no estímulo à curiosidade natural das crianças ao interagir com diferentes objetos. A proposta é não ter um foco na figura da professora passando conhecimentos aos alunos, mas que ela traga materiais e propostas para que os próprios alunos desenvolvam seu conhecimento a partir da manipulação dos objetos.

Como vimos, essa oficina tem uma proposta interdisciplinar e traz um pouco da a metodologia de Design participativo aplicada a um trabalho educativo para crianças. O Design como área fluida, que lida com diferentes áreas de conhecimento e com o desenvolvimento de projetos de forma não-linear, em que as situações que se apresentam levam a um novo desdobramento possível do projeto. Os objetos também são vistos não como fins em si, mas como mediações entre as pessoas - eles estão sempre possibilitando relações. Nessa oficina, as crianças podem, de forma não sistemática, ter a experiência de um projeto coletivo. Podem aprender mais sobre a natureza de diferentes materiais e ter a experiência de diálogo e coautoria na criação de um objeto.

\section{REFERÊNCIAS}

BENJAMIN, Walter. Reflexões sobre a criança, o brinquedo e a educação. São Paulo: Editora 34, 2009.

CÔRTES, Carlos André Lameirão. Construção de casa e pensamento com terra e bambu: Utilizando a pesquisa e a produção material de um processo construtivo com matérias naturais para fins educacionais. Orientador: José Luis Mendes Ripper. Dissertação (mestrado) Pontifícia Universidade Católica do Rio de Janeiro, Departamento de Artes \& Design, 1999.

FULLER, R. Buckminster. Buckminster Fuller on Education. Amherst: The University of Massachussets Press, 1979.

FULLER, R. Buckminster. Education Automation: Comprehensive Learning for Emerging Humanity. Baden, Switzerland: Lars Müller Publishers, 2010.

ILLICH, Ivan. A convivencialidade. Lisboa: Publicações Europa-América, 1973.

ILLICH, Ivan. Deschooling Society. New York: Harper \& Row Publishers, 1970.

SIEDEN, Lloyd Steven. Buckminster Fuller's Universe - His Life and Work. USA: Perseus Publishing, 1989. 


\section{SOBRE AS AUTORAS:}

\section{Julia Teles da Silva}

Doutora em Design pela Pontifícia Universidade Católica do rio de Janeiro (PUC-Rio). Professora Visitante na Universidade Federal de Campina Grande (UFCG). Docente do Programa de Pós-Graduação em Disgner da UFCG, na linha de pesquisa Informação, Comunicação e Cultura. E-mail: julitateles@gmail.com

(iD http://orcid.org/0000-0002-8532-1860

\section{Jackeline Lima Farbiarz}

Doutora em Educação pela Universidade de São Paulo (USP). Professora da Pontifícia Universidade Católica do rio de Janeiro (PUC-Rio). Pesquisadora no Programa de PósGraduação em Artes e Design. Coordenadora do Laboratório Linguagem, Interação e Construção de Sentidos/Design. E-mail: jackeline@ puc-rio.br

(iD) http://orcid.org/0000-0003-1329-0695 